\title{
Application of Leading Mixed Teaching Mode in the Teaching of Material Mechanics Course
}

\author{
Yun-Xin CHEN
}

School of Electromechanical \&Architectural Engineering, Jianghan University, Wuhan, 430056, China

2506271319@qq.com

\begin{abstract}
Keywords: Leading the Mixed Teaching; Mechanics of Materials; Innovation Capacity; Teaching Reform.
\end{abstract}

\begin{abstract}
Online learning has become an important learning method, and online education platform has been widely used. Leading mixed teaching is a new teaching model that combines traditional classroom teaching with online teaching. It can well solve the problem that online education based on autonomous learning mode places too much emphasis on students 'independent online learning and ignores the role of teachers. Or still only pay attention to the problem that the classroom does not really make good use of the network platform, and this article discusses the application of the leading mixed teaching model in practical teaching through the online course construction of material mechanics, aiming at the teaching status quo and existing problems of the "material mechanics" course. According to the training requirements of engineering majors, this paper puts forward new ideas and suggestions for teaching reform of material mechanics through in-depth analysis of the characteristics of MOOCs teaching model, which provides a guarantee for the cultivation of students innovative ability.
\end{abstract}

\section{Introduction:}

"Material Mechanics" is one of the important basic courses for materials forming and controlling engineering, mechanical design and manufacturing and automation, automotive service engineering and other majors in local undergraduate colleges. It is an important part of the overall knowledge structure and capability structure for training applied talents. For the follow-up "Mechanical Principles" and "Mechanical Design" courses to make a good foundation for the study, played an irreplaceable role in other courses; Learning material mechanics plays an important role in cultivating students 'learning methods and forming engineering concepts. With the rapid development of science and technology and the continuous enrichment of the teaching content of this course, the requirements for teaching are also getting higher and higher. But at present material mechanics course in teaching content, teaching methods, teaching methods and experimental skills are difficult to meet the requirements of teaching reform and innovative personnel training goals. Therefore, the characteristics of the material mechanics course need to introduce a new teaching model such as mixed classroom to stimulate students learning enthusiasm, which provides students with innovative ability training.

\section{Leading the design of a mixed teaching model:}

Under the leadership of the mixed teaching model, teachers can carefully select the classroom teaching content, select its key points and difficulties, make students understand and absorb as much as possible within the limited classroom teaching time, and put part of the teaching content that is relatively easy to self-study into extra-curricular online learning. Students can also complete courseware learning, data collection, and homework submission online through the Internet, because these teaching activities can be completed online or must be submitted online. At the same time, in the extra-curricular teaching, through the QQ discussion group and WeChat, online or offline communication and problem solving, to master the initiative of learning. For the typical and 
representative learning difficulties encountered by students in learning, master the rhythm and specific content of interactive discussion; For the difficult problems encountered by individual students, teachers and students can use QQ and other instant messaging software to achieve extra-curricular personalized learning guidance and in-depth guidance for students to study ${ }^{[1]}$.

How to refine the key content, key points and difficult points of the course and make the classroom content concise and concise is one of the main research contents in the design of the leading mixed learning model under the leading mixed teaching model. For some basic knowledge and practical teaching content with strong application, how to allow students to study and think first through teaching materials after reasonable combing by teachers, and then according to the network teaching courseware and online teaching resources to carry out comprehension learning. It is also a problem that must be considered in the design of the leading mixed learning model.

After the completion of the study of the stress state related content, a lifting platform working video was introduced. The middle hinge is used between the members in the structure, the left end of the bottom member is a fixed hinge base, and the right end is a roller constraint; The left end of the member connected to the support platform is a fixed column hinge base, and the right end is a roller constraint. When the lifting platform is working, the roller can move along the tangent line of the support surface to complete the lifting and falling of the work platform. The students are required to establish their mechanical model according to the structure, and solve the binding force of each component, and analyze which component in the entire structure bears the largest and most unsafe reaction force; On the basis of this, students are further asked to discuss if the stress value of the structure is to be measured on the spot to detect whether the strength of the structure meets the requirements during work, or whether the structure is to be optimized for strength design, and how to determine the measurement point. That is, reduce the workload of the test and do not miss the danger point; How to determine whether the measurement point is treated as a one-way stress state or as a plane stress state based on the calculated binding force, and for this structure we have completed the stress measurement of the structure under empty load, full load and overload conditions. After the students have completed the discussion, the measured results are announced, and the students are allowed to evaluate their own analysis results. In this way, students have experienced a whole process of solving engineering problems using the knowledge of material mechanics learned, cultivated the ability and method to solve engineering problems, and increased engineering literacy ${ }^{[2]}$.

How to achieve gradual and gradual teaching content, and strive to avoid direct indoctrination of teachers in classroom teaching, resulting in students struggling to cope with the teaching status, because compared to traditional classroom teaching, the classroom teaching content under the leading-style mixed learning mode is more difficult and intensive knowledge point, Students have a high learning pressure, which is also a problem that must be paid attention to in the design of the leading mixed learning model.

Students can use the learned mechanical knowledge to design experimental goals, methods, and analysis, and can obtain various open results. For example: The impact of contact area and weight on friction can be verified by applying a simple slope descent experiment designed by the surrounding items. Through design experiments, students are promoted to understand and understand the theoretical knowledge they have learned, cultivate students 'innovative spirit, and strengthen students' ability to discover problems, analyze problems, and solve problems.

How to conduct effective offline coaching and testing? How to promote students 'independent learning through teachers' active guidance in the network platform? How to improve the ability of students to solve problems on the premise of not significantly increasing the burden of teachers 'teaching is also an important problem that must be solved in the design of the leading mixed learning model.

Construct the group mutual evaluation mechanism based on the open problem. Construct the mutual evaluation learning mechanism, realize the "multi-to-many" video homework students to judge each other. This paper studies and formulates the assessment assistant mechanism based on MOOCs and WeChat platform teaching mode, and objectively evaluates the learning effect of 
students. Under the mutual evaluation mechanism, students anonymously judge each other's multiple video assignments, stimulate students 'sense of self-learning, guide students to relate to each other, and increase the flexibility of the course.

\section{Leading the Practice of Mixed Teaching Model:}

In our school, under the lead of mixed learning mode, the teaching hours of the "Material Mechanics" course are divided into classroom teaching hours and extra-curricular network teaching hours. The online course center of Jianghan University has been operating on the Superstar network platform for many years. It has established a relatively complete online teaching platform with courseware and video data download, online assignments, and online questions and answers.

For mixed teaching, first of all, we need to carefully design the classroom teaching content, fully mobilize the enthusiasm of students in the classroom, and encourage students to actively review and prepare the teaching content under the class by arranging certain tasks after each class. Through online video and answering questions to deepen the understanding of the undigested knowledge in the classroom, and through online message discussion or QQ group can achieve a combination of centralized counseling and individual counseling teacher and student communication methods, so as to improve teaching efficiency ${ }^{[3]}$.

\section{Summary}

Leading the application of the mixed teaching model in the "material mechanics" course, ensuring that under the premise of basic knowledge teaching, through classroom communication and interaction under the class, the interactive discussion between teachers and students has been enhanced, and the knowledge of students has been expanded. It has deepened students 'understanding of the curriculum, strengthened and cultivated students' ability to use the knowledge learned to comprehensively analyze and solve practical problems, cultivated students 'spirit of innovation, strengthened students' engineering practice ability, and at the same time, it also has higher requirements for the comprehensive quality of teachers. According to the characteristics of the current students, the new and effective teaching model is used to train outstanding engineering talents with engineering literacy for the national industry, provide experience for the establishment and improvement of the MOOCs platform, and contribute to the Advancement of China's educational development.

\section{Acknowledgement}

This research was financially supported by Teaching reform and practice of material mechanics course based on the training of creative talents in the era of MOOCS Project number: 2015275; Jianghan University Online CourseMaterial mechanics: 201719.

Author introduction: Chen Yunxin (1972-), female, Hubei Han, professor of Jianghan University, teaching and research mainly engaged in basic mechanics.

Tel: 13080651852 e-mail: 2098558413@qq.com

Address: Mechanical Department of Wuhan City Hubei Province Chamber of Jianghan University and Institute of architecture and Engineering (430056)

\section{References}

[1] Zhangqiliang, Wang Aichun. A Study of New Hybrid Teaching Model Based on "Flip Classroom"[J]. Modern educational techniques, 2014(4): 27-32.

[2] Zhang Tao Give full play to the teaching advantages of the Internet and enjoy the wonderful lessons and flip the classroom, 2015 (5): 165

[3] Li Fengqing, Theoretical Foundation and Teaching Design of Mixed Teaching[J]. Modern educational techniques, 2016(9):18-24. 